\title{
Capability Level Measurement Using COBIT 5 (Case Study: PT. Jasa Cendekia Indonesia)
}

\author{
Abdurrahman Harits ${ }^{1}$, Gilang Muhamad Noer ${ }^{2}$, Aris Puji Widodo ${ }^{3}$ \\ 1,2,3Postgraduate school, Diponegoro University, Semarang, Indonesia \\ Email: 1abdurharits@gmail.com, ${ }^{2}$ gilangmuhamadn@gmail.com, ${ }^{3}$ arispw@gmail.com
}

\begin{abstract}
The rapid development of information technology (IT) has become a challenge for companies in managing IT. IT needs to be managed properly to enable companies to take full advantage of their IT, PT. Jasa Cendekia Indonesia cooperates with third-party vendors, both in the use of applications and IT infrastructure, but in practice there are problems, their presence has not run optimally and adjustments related to IT integration due to collaboration with several vendors need to be done. Therefore, it is necessary to measure the Capability Level to determine the extent of IT operational management at PT. Jasa Cendekia Indonesia, to be an evaluation material, so that the IT applied to the company can provide services as expected. The purpose of this study was to identify the conditions for implementing IT operational management using a quantitative method referring to COBIT 5 domain DSS01 (Manage Operations), conducting initial observations of the company's condition and conducting a questionnaire to stakeholders, then measuring the Capability Level. The results showed that the Capability level of PT . Jasa Cendekia Indonesia in managing IT operations is generally at level 2 (Managed process), there are still processes that have not been fulfilled, the expected goal is level 3 (Established process). recommendations are given as a step to support optimal performance and achieve the expected goals.
\end{abstract}

Keywords: Capability Level, COBIT 5, DSS01, PT. Jasa Cendekia Indonesia

\section{PENDAHULUAN}

Untuk dapat meningkatkan daya saing, organisasi atau perusahaan perlu menerapkan teknologi informasi pada proses bisnisnya[1]. Tata Kelola TI membahas penyelarasan bisnis dan TI yang memungkinkan pelaku bisnis dan TI dapat melaksanakan tanggung jawabnya untuk mendukung proses bisnis [2]. Masalah utama yang sering terjadi pada tata kelola TI, yaitu strategi TI yang tidak selalu sejalan dengan strategi perusahaan, sehingga diperlukan evaluasi dalam tata kelola TI [3]. Evaluasi adalah proses yang dilakukan untuk melihat bagaimana keberhasilan suatu program yang di susun untuk dapat mendukung suatu tujuan [4]. 
Pengukuran capability level sebagai bahan evaluasi dapat dilakukan dengan menggunakan COBIT 5, COBIT 5 merupakan kerangka kerja tata kelola TI yang terkenal untuk menerapkan serangkaian praktik terbaik untuk manajemen, kontrol, dan jaminan TI [5]. COBIT 5 di terbitkan oleh ISACA untuk menyelidiki masalah bisnis dan TI, kerangka kerja ini digunakan untuk mengidentifikasi kekurangan control internal, risiko kepatuhan dan risiko TI [6]. Domain manage operations (DSS01) merupakan salah satu domain pada COBIT 5 yang berisi tentang pengelolaan dan juga monitoring pada koordinasi antara prosedur operasional dan pelaksanaan kegiatannya agar layanan bagi pihak internal ataupun eksternal dapat tersedia dengan baik [7].

COBIT 5 adalah kerangka kerja yang membantu perusahaan untuk menciptakan nilai optimal dari penggunaan teknologi informasi dengan menyeimbangkan antara manfaat dan resiko [8]. COBIT 5 berperan untuk meningkatkan manajemen pengelolaan TI yang lebih baik (good governance). Implementasi penerapan COBIT 5 dapat dilakukan pada berbagai perusahaan salah satunya yaitu PT. Jasa Cendekia Indonesia. Perusahaan ini didirikan oleh Andi Muhammad Hatta sejak tahun 1992 yang berfokus pada bisnis perekrutan, outsourcing, pelatihan dan konsultasi. Kekuatan perusahaan ini dalam mengelola solusi ketenagakerjaan (outsourcing dan rekrutmen) di Indonesia. Saat ini PT. Jasa Cendekia Indonesia mengelola lebih dari 500 karyawan outsourcing, menempatkan ratusan orang Indonesia ke pasar kerja dan melayani lebih dari 30 perusahaan multinasional dan perusahaan domestik dari berbagai industri.

Saat ini, PT. Jasa Cendekia Indonesia belum optimal dalam menerapkan manajemen pengelolaan operasional TI dan masih memiliki ketergantungan yang besar terhadap vendor pihak ketiga baik dalam penggunaan aplikasi maupun perancangan infrastruktur TI, kemudian munculnya permasalahan terkait aplikasi yang sudah dalam perjanjian kontrak jangka panjang sebelumnya menghasilkan penyimpanan besar serta kehadirannya yang tidak begitu maksimal setelah digunakan selama beberapa tahun, juga permasalahan terkait integrasi TI. Penelitian ini bertujuan untuk mengidentifikasi kondisi operasional TI dan melakukan pengukuran terhadap tingkat kapabilitas dari PT. Jasa Cendekia Indonesia yang berguna sebagai bahan evaluasi untuk dijadikan rekomendasi agar membantu perusahaan dalam mengelola aktifitas bisnis. Penelitian ini menggunakan COBIT 5 yang merupakan kerangka menyeluruh agar dapat membantu mencapai tujuannya untuk tata kelola dan manajemen TI perusahaan [9].

Domain yang digunakan dalam penelitian ini adalah DSS, domain ini berfokus pada penilaian pelayanan teknologi informasi, pengiriman serta dukungan termasuk pengelolaan masalah pada perusahaan agar kontinuitas dan kualitasnya pada tahap scaling-up tetap terjaga, dengan sub domain DSS01 yang sebelumnya telah dijelaskan bahwa sub domain ini berisi tentang pengelolaan dan juga 
Vol. 3, No. 2, June 2021

p-ISSN: 2656-5935 http://journal-isi.org/index.php/isi e-ISSN: 2656-4882

monitoring pada koordinasi antara prosedur operasional dan pelaksanaan kegiatannya, yang cocok untuk mengevaluasi permasalahan yang ada dalam perusahaan. Salah satu contoh penerapan domain ini terdapat pada penelitian yang dilakukan oleh Ricky Darius, Eko Darwiyanto, dan Gede Agung pada PT. Inovasi Tjaraka Buana yang menghasilkan rekomendasi yang berasal dari analisis kebutuhan terhadap proses dan aktivitas yang akan dilakukan terkait dengan tata kelola TI perusahaan [10]. Terdapat penelitian yang dilakukan oleh Andreas Wiraniagara dan Agustinus Fritz berupa analisis tata kelola TI menggunakan COBIT 5 domain DSS pada Yayasan Eka Tjipta, hasil dari penelitian ini berupa rekomendasi dari permasalahan dalam penerapan tata kelola TI di Yayasan Eka Tjipta [11]. Kemudian penelitian yang dilakukan oleh H. Prasojo dan Pujiono berupa analisis tata kelola TI menggunakan COBIT 5 domain DSS01, hasil dari penelitian ini berupa rekomendasi untuk strategi perbaikan dalam penerapan tata kelola TI di BPS Provinsi Jawa Tengah [12]. Dan penelitian yang dilakukan R. Putri berupa penilaian kapabilitas proses tata kelola TI berdasarkan proses DSS01 pada COBIT 5, hasil dari penelitian ini dirumuskan langkah-langkah perbaikan yang dapat dilakukan oleh organisasi agar tingkat kapabilitas proses DSS01 dapat meningkat sehingga pemanfaatan TI pada organisasi menjadi lebih optimal sesuai dengan investasi yang dikeluarkan [13].

\section{METODOLOGI PENELITIAN}

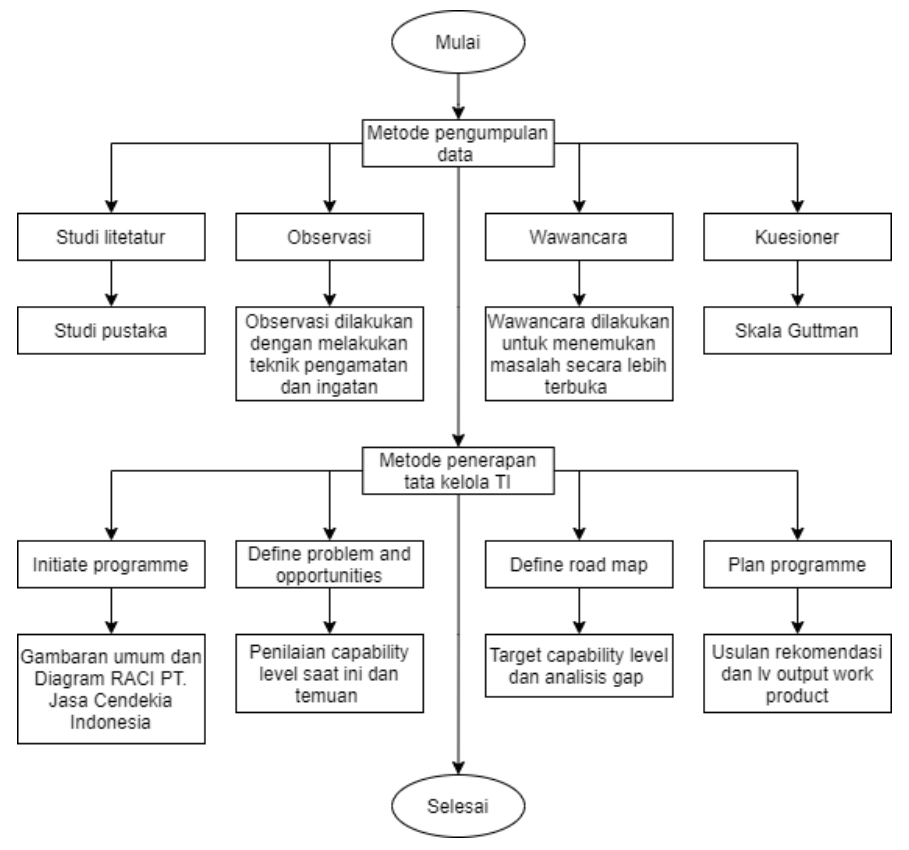

Gambar 1. Kerangka Penelitian 
Vol. 3, No. 2, June 2021

p-ISSN: 2656-5935 http://journal-isi.org/index.php/isi

e-ISSN: 2656-4882

Framework COBIT 5 digunakan sebagai alat penilaian seperti mengukur tingkat kemampuan tata kelola TI, mengembangkan model kompetensi untuk IT personnel di enterprise architecture, dan melakukan analisis risiko [14]. Dalam penelitian di PT. Jasa Cendekia Indonesia, peneliti menggunakan pendekatan kuantitatif yang bersumber dari para stakeholder yang terkait langsung dengan proses pengelolaan TI. Langkah-langkah dalam metode ini berupa pengumpulan data, perhitungan kapabilitas, dan analisis terhadap data untuk mendapatkan gambaran dan rekomendasi yang sesuai bagi perusahaan.

Penelitian ini terdiri atas 2 tahap yaitu tahap pertama berupa pengumpulan data yang berguna untuk mengetahui permasalahan dan kondisi awal perusahaan, sebagai bahan untuk merumuskan penelitian. Permasalahan kinerja, dan tujuan dari organisasi dapat menjadi pendorong akan adanya perubahan [16].

Tahap ini diawali dengan melakukan studi literatur dengan cara mengumpulkan data yang berhubungan dengan penerapan COBIT 5 yang berasal dari berbagai sumber, buku, artikel dan jurnal. Observasi dilakukan dengan mengamati penerapan TI yang ada pada PT. Jasa Cendekia Indonesia. Wawancara dilakukan untuk menemukan permasalahan secara lebih terbuka, kemudian kuesioner dirumuskan berdasarkan kerangka kerja COBIT 5 merujuk pada skala Guttman untuk menghitung capability level pada setiap pertanyaan. Selanjutnya adalah merumuskan RACI chart untuk menentukan responden dari hasil observasi dan wawancara. Diagram ini digunakan untuk penggambaran responden dalam kuesioner capability level yang akan diberikan. Sehingga data yang di hasilkan spesifik dan sesuai dengan apa yang di butuhkan [15].

Tahap kedua yang pertama adalah initiate programme, tahap ini menjelaskan tentang penggerak pada organisasi, dengan tujuan mendapatkan pemahaman mengenai tugas, wewenang dan tujuan pada organisasi ini, untuk menentukan responden dengan menggunakan diagram RACI untuk menggambarkan peran-peran dari para stakeholder dalam PT. Jasa Cendekia Indonesia yang terkait langsung dengan proses atau domain yang diambil dalam pengelolaan TI. Kemudian adalah define problems and opportunities yang menjelaskan tentang posisi dan temuan pada tatakelola TI di organisasi saat ini, hal ini dicapai dengan dilakukan pengukuran dan penilaian tingkat kemampuan saat ini berdasarkan hasil kuesioner capability level yang telah diberikan kepada stakeholder. Selanjutnya define road map tahap ini menjelaskan tentang target perbaikan yang akan dilakukan organisasi yang tujuannya untuk menetapkan tager kemampuan pada proses yang dipilih, kemudian analisis gap antara kondisi saat ini dan kondisi yang diharapkan, kemudian tahap yang terakhir plan programme pada tahap ini menjelaskan tentang usulan atau rencana solusi perbaikan dalam tata kelola teknologi informasi di PT. Jasa Cendekia Indonesia, rencana solusi tersebut ditujukan untuk proses domain yang menjadi fokus pada penelitian ini yaitu proses pengelolaan operasional (DSS01). 
Vol. 3, No. 2, June 2021

p-ISSN: 2656-5935 http://journal-isi.org/index.php/isi e-ISSN: 2656-4882

\section{HASIL DAN PEMBAHASAN}

\subsection{Hasil Pengumpulan Data}

Berdasarkan hasil pengumpulan data diperoleh pemahaman tentang PT. Jasa Cendekia Indonesia meliputi struktur organisasi, tujuan, tugas dan wewenang. Pada salah satu departemen bernama Building Improvement and Information Technology Service bertugas melaksanakan pembinaan, pengembangan dan standarisasi di bidang teknologi informasi, sistem informasi, juga sistem komunikasi data yang ada di perusahaan tersebut, telah melakukan kerjasama dengan vendor terkait TI baik aplikasi, jaringan, dan juga infrastruktur.

Dalam penerapan manajemen TI, PT. Jasa Cendekia Indonesia memiliki ketergantungan yang besar pada beberapa vendor pihak ketiga baik dalam pemanfaatan aplikasi serta infrastruktur TI, lalu munculnya masalah terkait aplikasi yang sudah dalam perjanjian kontrak jangka panjang sebelumnya yaitu menghasilkan penyimpanan memori yang besar serta kehadirannya tidak begitu maksimal setelah digunakan selama beberapa tahun, kemudian karena tidak hanya bekerja sama dengan satu vendor melainkan beberapa vendor dalam pemanfaatan aplikasi dibutuhkan migrasi untuk melakukan penyesuaian terkait integrasi supaya tetap pada tujuan yang diharapkan.

\subsection{Penerapan Tata Kelola TI}

1) Initiate Programme

Berdasarkan diagram RACI dibutuhkan 3 responden dalam kuesioner capability level adalah sebagai berikut:

Tabel 1. Identifikasi diagram RACI

\begin{tabular}{|c|c|c|}
\hline No & RACI Roles & Organitational Roles \\
\hline 1 & Head of IT Operation & $\begin{array}{c}\text { Kepala Bagian Building Improvement } \\
\text { Innovation \& IT Service }\end{array}$ \\
\hline 2 & Business Continuity Manager & $\begin{array}{c}\text { Kepala Bagian Manpower Outsourcing } \\
\text { Operation Division }\end{array}$ \\
\hline 3 & Service Manager & Staff Virtual Supervising \& Call Center \\
\hline
\end{tabular}

\section{2) Define Problems and Opportunities}

Diberikan kuesioner kepada 3 responden berdasarkan tabel identifikasi diagram RACI yang kemudian data diolah, hasil dan temuannya adalah sebagai berikut: 


\section{Journal of Information Systems and Informatics}

Vol. 3, No. 2, June 2021

p-ISSN: 2656-5935 http://journal-isi.org/index.php/isi e-ISSN: 2656-4882

Tabel 2. Rekapitulasi capability level

\begin{tabular}{|c|l|c|}
\hline Domain & \multicolumn{1}{|c|}{ Proses } & Capability level \\
\hline \multirow{5}{*}{ DSS01 } & $\begin{array}{l}\text { DSS01.1 ( Perform } \\
\text { Operational Procedures) }\end{array}$ & 2.43 \\
\cline { 2 - 3 } & $\begin{array}{l}\text { DSS01.2 ( Manage } \\
\text { Outsourced IT Service) }\end{array}$ & 2.80 \\
\cline { 2 - 3 } & $\begin{array}{l}\text { DSS01.3 (Monitor IT } \\
\text { Infrastructure) }\end{array}$ & 2.90 \\
\cline { 2 - 3 } & $\begin{array}{l}\text { DSS01.4 ( Manage } \\
\text { Environtment) }\end{array}$ & 2.87 \\
\cline { 2 - 3 } & $\begin{array}{l}\text { DSS01.5 (Manage } \\
\text { Facilities) }\end{array}$ & 3.00 \\
\hline \multicolumn{2}{|c|}{ Rekapitulasi Current Capability } & 2.80 \\
\hline
\end{tabular}

Dari proses tersebut diperoleh temuan-temuan, pada DSS01.1 (manage operational procedure) ditemukan adanya perencanaan terhadap pengembangan dan pemeliharaan prosedur operasional dan aktivitas yang terkait agar layanan di organisasi berjalan seluruhnya, kemudian perencanaan terhadap pemrosesan data diproses baik dan tepat waktu. Adanya perencanaan terhadap penjadwalan, pengambilan juga pencatatan backup yang sesuai dengan prosedur yang telah ditetapkan, di buktikan dengan adanya SOP internal IT Infrastuktur Jasa Cendekia Indonesia dan integrasi database JEDS (Jasacendekia Electronic Document System).

Pada DSS01.2 (manage outsourced IT service) ditemukan adanya perencanaan terhadap keamanan informasi proses dan prioritas sesuai kontrak dan SLA (Service Level Agreement) dengan hosting dari pihak ketiga, kemudian adanya perencanaan terhadap kegiatan operasional perusahaan dan IT proses requirement dan prioritas untuk service delivery mengikuti sesuai dengan kontrak SLA dengan hosting dari pihak ketiga. Adanya perencanaan terhadap integrasi internal proses manajemen TI yang bersifat penting dengan penyedia layanan outsource, dibuktikan dengan adanya SOP vendors IT service and infrastrukture Jasa Cendekia Indonesia.

Pada DSS01.3 (monitor IT infrastructure) adanya perencanaan, monitoring, dan penyesuaian dalam proses identifikasi tingkat informasi berdasarkan pertimbangan resiko dan kinerja, kemudian adanya perencanaan, monitoring dan penyesuaian dalam pengidentifikasian dan pemeliharaan daftar aset infrastuktur, dipantau berdasarkan layanan yang bergantung pada hal tersebut. Adanya perencanaan, monitoring dan penyesuaian dalam pencatatann peristiwa-peristiwa dan mempertahankan mereka untuk jangka waktu yang tepat untuk membantu dalam penyidikan di masa depan, berdasarkan adanya bukti laporan monitoring infrastruktur TI Jasa Cendekia Indonesia dan service request and management incident Jasa Cendekia Indonesia. 
Vol. 3, No. 2, June 2021

p-ISSN: 2656-5935 http://journal-isi.org/index.php/isi e-ISSN: 2656-4882

Pada DSS01.4 (manage the environment) ditemukan adanya perencanaan, monitoring, dan penyesuaian dalam pengidentifikasian dan mengetahui tentang letak-letak kecelakaan yang dapat terjadi baik secara natural ataupun buman error, dan menilai efeknya terhadap fasilitas TI, kemudian adanya perencanaan, monitoring dan penyesuaian terhadap pengidentifikasian bagaimana sebuah peralatan TI terlindungi dari ancaman lingkungan. Memastikan bahwa peratuan itu membatasi aktifitas pada area yang sensitif yang dapat menimbulkan resiko kebakaran, berdasarkan adanya bukti service request dan management incident Jasa Cendekia Indonesia dan manajemen keaman Jasa Cendekia Indonesia.

Pada DSS01.5 (manage facilities) ditemukan adanya bukti perencanaan, penyesuaian dan monitoring kebutuhan fasilitas TI untuk melindungi dari fluktuasi daya dan kehilangan daya, pembelian UPS (Uninterruptible power supply's) untuk mendukung keberlanjutan perusahaan, kemudian adanya perencanaan, penyesuaian dan monitoring terhadap rutinitas pemeriksaan UPS, dan memastikan bahwa listrik dapat diganti ke UPS tanpa mengganggu operasi bisnis. Adanya perencanaan dan penyesuaian terhadap teknis pengkabelan yang terstruktur dan terorganisir. Struktur pengkabelan harus didokumentasi, berdasarkan adanya SOP monitoring server, UPS skala menengah, IT Blueprint.

\section{3) Define Road Map}

Perolehan hasil perhitungan tersebut menunjukan bahwa kemampuan PT. Jasa Cendekia Indonesia saat ini sebagian telah berada pada level 2 yang kemudian menetapkan target berdasarkan proses yang dipilih. Dapat disimpulkan bahwa proses telah sebagian besar telah diimplementasikan, sebagian besar tujuan prosesnya telah dicapai, berikut adalah grafik capability level domain DSS01 :

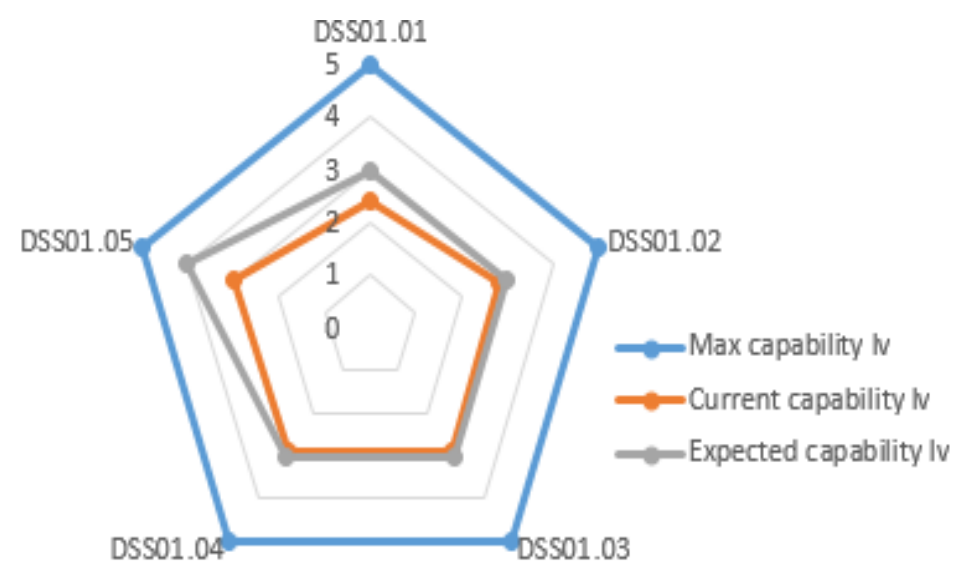

Gambar 5. Grafik capability level pada domain DSS01 
Vol. 3, No. 2, June 2021

p-ISSN: 2656-5935 http://journal-isi.org/index.php/isi e-ISSN: 2656-4882

Tabel 3. Target dan gap capability level domain DSS01

\begin{tabular}{|c|l|c|c|c|}
\hline Domain & \multicolumn{1}{|c|}{ Proses } & $\begin{array}{c}\text { Current } \\
\text { capability }\end{array}$ & $\begin{array}{c}\text { Expected } \\
\text { Capability }\end{array}$ & Gap \\
\hline \multirow{5}{*}{ DSS01 } & $\begin{array}{l}\text { DSS01.1 (Perform } \\
\text { Operational Procedures) }\end{array}$ & 2.43 & 3 & 0.57 \\
\cline { 2 - 5 } & $\begin{array}{l}\text { DSS01.2(Manage } \\
\text { Outsourced IT Service) }\end{array}$ & 2.80 & 3 & 0.20 \\
\cline { 2 - 5 } & $\begin{array}{l}\text { DSS01.3 (Monitor IT } \\
\text { Infrastructure) }\end{array}$ & 2.90 & 3 & 0.10 \\
\cline { 2 - 5 } & $\begin{array}{l}\text { DSS01.4 (Manage } \\
\text { Environtment) }\end{array}$ & 2.87 & 3 & 0.13 \\
\cline { 2 - 5 } & $\begin{array}{l}\text { DSS01.5 (Manage } \\
\text { Facilities) }\end{array}$ & 3.00 & 4 & 1 \\
\hline
\end{tabular}

Berdasarkan tabel 3. terdapat perbedaan, dan diperoleh gap diantara keduanya. Analisa gap setiap proses pada DSS01, yaitu pada DSS01.1 tidak adanya implementasi terhadap bukti jadwal kegiatan operasional untuk mengelola kinerja operasional agar mendukung semua layanan yang berkelanjutan sehingga tepat waktu dalam verifikasi terhadap data output dan mampu memproses ulang kebutuhan-kebutuhan perusahaan, maka pada proses ini yang menjadi kekurangan adalah jadwal kegiatan IT operation.

Pada DSS01.2 tidak adanya implementasi terhadap perencanaan untuk audit independen dan jaminan operational environment dari penyedia outsource untuk memastikan requirement yang sudah disetujui telah disebut, pada proses ini yang menjadi kekurangan adalah independent assurance plans.

Pada DSS01.3 tidak adanya implementasi dalam pendefinisian dan penerapan aturan yang mengidentifikasi threshold violation dan event conditions, tidak adanya implementasi dalam prosedur untuk memantau pencatatan event dan melakukan tinjauan rutin, pada proses ini yang menjadi kekurangan adalah facilities assessment reports dan asset monitoring rules and event conditions.

Pada DSS01.4 tidak adanya implementasi terhadap rutinitas memonitor alat-alat yang dapat mendeteksi ancaman lingkungan, pada proses ini yang menjadi kekurangan adalah environmental policies.

Pada DSS01.5 tidak adanya implementasi terhadap kepastian bahwa bagian tempat penyimpanan fasilitas TI memiliki lebih dari satu sumber daya dan memisahkan jalur masuk dayanya, kemudian tidak adanya implementasi terhadap kepastian bahwa pengkabelan eksternal ke area TI berada dibawah tanah atau memiliki perlindungan yang lain, maka pada proses ini yang menjadi kekurangannya adalah Back up UPS dan pengkabelan yang sederhana. 
Vol. 3, No. 2, June 2021

p-ISSN: 2656-5935 http://journal-isi.org/index.php/isi e-ISSN: 2656-4882

\section{4) Plan Programme}

Usulan dan rencana solusi perbaikan yang dilakukan untuk mencapai level 3 output work product. Rekomendasi pada DSS01.1, PT Jasa Cendekia Indonesia membuat jadwal kegiatan operasional untuk mengelola kinerja operasional agar mendukung semua layanan yang berkelajutan sehingga tepat waktu dalam verifikasi terhadap data output dan mampu memproses ulang kebutuhan-kebutuhan organisasi.

Pada DSS01.2 direkomendasikan untuk membuat tim audit independen dan jaminan dari lingkungan operasional dari penyedia outsource untuk memastikan requierement yang sudah disetujui.

Pada DSS01.3 direkomendasikan untuk membuat tim pencatatan peristiwaperistiwa untuk membantu dalam penyelidikan di masa depan. Kemudian perlu mengadakan pengidentifikasian dan pemeliharaan daftar asset infrastruktur.

Pada DSS01.4 direkomendasikan untuk mengadakan rutinitas mengenai monitoring alat-alat yang dapat mendeteksi ancaman lingkungan organisasi, kemudian membuat kebijakan lingkungan organisasi, yang dimana terdapat penawaran khusus dengan manajemen lingkungan TI, termasuk data center dan ruang penyimpanan.

Pada DSS01.5 direkomendasikan untuk membuat bagian tempat penyimpanan fasilitasi TI memiliki lebih dari satu sumber daya dan memisahkan jalur masuk dayanya, membuat pengkabelaan ekstrenal ke area TI berada dibawah tanah atau memiliki perlindungan yang lain, kemudian membuat laporan penilaian fasilitas berkala.

\section{KESIMPULAN}

Berdasarkan hasil penelitian yang telah dilakukan di PT. Jasa Cendekia Indonesia menggunakan COBIT 5, didapatkan kesimpulan bahwa tingkat kemampuan PT. Jasa Cendekia Indonesia dalam sub domain Deliver, Service, and Support (DSS01) berada pada level 2 dengan nilai 2.80. tingkat kemampuan yang diharapkan adalah level 3 yaitu penyesuaian penetapan dan pengelolaan proses sejalan dengan tujuan prosesnya. Namun pada kondisinya, masih adanya proses yang belum dapat terpenuhi sepenuhnya. Berdasarkan hal tersebut peneliti memberikan rekomendasi langkah pencapaian untuk mengoptimalkan kinerja TI dan mencapai target tingkat kemampuan level 3.

\section{Daftar Pustaka}

[1] H. T. Sihotang, M. Zarlis, S. Efendi, D. Jollyta, and Husain, "Evaluation 
of Maturity Level of Information and Communication Technology (ICT) Governance with CobIT 5.0 Case Study: STMIK Pelita Nusantara Medan," J. Phys. Conf. Ser., vol. 1255, no. 1, pp. 0-6, 2019, doi: 10.1088/1742-6596/1255/1/012046.

[2] T. Huygh, S. De Haes, A. Joshi, and W. Van Grembergen, "Answering Key Global IT Management Concerns Through IT Governance and Management Processes: A COBIT 5 View," Proc. 51 st Hawaii Int. Conf. Syst. Sci., vol. 9, 2018, doi: 10.24251/hicss.2018.665.

[3] V. R. Aprilia, Harisno, and V. H. Kusumawardhana, "Evaluation of IT Governance on Core Banking System Development Project Using Framework COBIT 5: Case Study at PT Bank KEB Hana Indonesia," $1 s t$ 2018 Indones. Assoc. Pattern Recognit. Int. Conf. Ina. 2018 - Proc., pp. 233-239, 2019, doi: 10.1109/INAPR.2018.8627018.

[4] R. Yaniar Sianida, F. Nur Afiana, and R. Wahyudi, "IS Governance Evaluation Using COBIT 5 Framework on the Central Statistics Agency of Banyumas District," J. Comput. Sci. Eng., vol. 1, no. 1, pp. 1-9, 2020, doi: 10.36596/jcse.v1i1.9.

[5] A. Joshi, L. Bollen, H. Hassink, S. De Haes, and W. Van Grembergen, "Explaining IT governance disclosure through the constructs of IT governance maturity and IT strategic role," Inf. Manag., vol. 55, no. 3, pp. 368-380, 2018, doi: 10.1016/j.im.2017.09.003.

[6] K. H. Guo and B. L. Eschenbrenner, "CVS Pharmacy: An instructional case of internal controls for regulatory compliance and IT risks," J. Account. Educ., vol. 42, no. May 2017, pp. 17-26, 2018, doi: 10.1016/j.jaccedu.2017.11.001.

[7] Wella, "Audit Sistem Informasi Menggunakan Cobit 5 . 0 Domain DSS pada," Ultim. InfoSys, vol. VII, no. 1, pp. 38-44, 2016.

[8] S. N. S. Berlianna and A. R. P. Suprapto, "Evaluasi Tingkat Kapabilitas Sumber Daya Teknologi Informasi Pada Institut Teknologi Nasional Malang Menggunakan Kerangka Kerja Cobit 5," ... Pengemb. Teknol. Inf. ..., vol. 2, no. 10, 2018, [Online]. Available: http://jptiik.ub.ac.id/index.php/j-ptiik/article/view/2705.

[9] M. M. Rio Septian Hardinata, Wirda Fitriani, Cahyo Pramono and A. K. Husni Muharam Ritonga, Leni Marlina, Suheri, "Audit Tata Kelola Teknologi Informasi menggunakan Cobit 5 (Studi Kasus: Universitas Pembangunan Panca Budi Medan)," J. Tek. Dan Inform., vol. 6, no. 01, pp. 42-45, 2019.

[10] R. D. Putra, M. T. Eko Darwiyanto, S.T., and M. T. Gede Agung Ary Wisudiawan, S.Kom., “Audit Teknologi Informasi Dengan Menggunakan Framework COBIT 5 Domain DSS (Deliver, Service, And Support ) Pada PT . Inovasti Tjaraka Buana," eProceedings Eng., vol. 3, no. 1, pp. 930937, 2016, [Online]. Available: https://webcache.googleusercontent.com/search?q=cache:ydu2M8ljCTI 
J:https://openlibrary.telkomuniversity.ac.id/pustaka/files/114836/jurnal _eproc/audit-teknologi-informasi-dengan-menggunakan-frameworkcobit-5-domain-dss-deliver-service-and-support-pada-pt-i.

[11] A. Wiraniagara and A. F. Wijaya, "Analisis Tata Kelola Teknologi Informasi Menggunakan Framework Cobit 5 Domain Deliver Support and Service (Studi Kasus: Yayasan Eka Tjipta)," Sebatik, vol. 23, no. 2, pp. 663671, 2019, doi: 10.46984/sebatik.v23i2.831.

[12] H. P. Prasojo and Pujiono, "Analisis Tata Kelola Teknologi Informasi Dengan Menggunakan Framework Cobit 5 Domain DSS01 ( Manage Operations) Pada BPS Provinsi Jawa Tengah," J. JOINS Udinus, vol. 1, no. x, pp. 67-76, 2017.

[13] R. E. Putri, "Penilaian Kapabilitas Proses Tata Kelola TI Berdasarkan Proses DSS01 Pada Framework COBIT 5," J. CoreIT, vol. 2, no. 1, pp. $41-$ 54, 2016.

[14] S. A. Wulandari, A. P. Dewi, M. Rizki Pohan, D. I. Sensuse, M. Mishbah, and Syamsudin, "Risk assessment and recommendation strategy based on COBIT 5 for risk: Case study sikn Jikn helpdesk service," Procedia Comput. Sci., vol. 161, pp. 168-177, 2019, doi: 10.1016/j.procs.2019.11.112.

[15] S. D. Rehatta and A. D. Manuputty, "Measurement of the Maturity Level of IT Governance in Implementing Personnel Management Information System Using the MEA Domain COBIT 5 Framework In Regional Personnel, Education and Training Agency," J. Inf. Syst. Informatics, vol. 1, no. 2, pp. 123-135, 2019, doi: 10.33557/journalisi.v1i2.16.

[16] ISACA. and J. W. Lainhart, COBIT 5: A business framework for the governance and management of enterprise IT COBIT 5, vol. 34, no. 1. 2012. 